\title{
Application of Artificial Intelligence and Blockchain in healthcare management - donor organ transplant system
}

Swapnil Morande ${ }^{1 *}$, Marialuisa Marzullo ${ }^{2}$

Department of Economics, Management, Institutions, University of Naples FEDERICO II, Italy ${ }^{1,2}$ swapnil.morande@unina.it ${ }^{{ }^{*}}$, marialuisa.marzullo@unina.it ${ }^{2}$

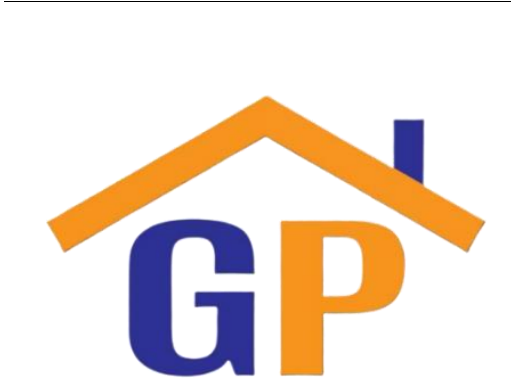

Article History

Received on 10 September 2020 Revised on 25 September 2020 Accepted on 28 September 2020

\begin{abstract}
Purpose: Research ventures to expand the reach of organ transplant mechanisms to improve the abysmally low organ transplant rate in the country. The research deploys state of the art technologies to promote deceased organ donation using the donor organ transplant system.
\end{abstract}

Research methodology: The exploratory study focuses on addressing the limitation of resources using a Socio-material view. The research utilizes qualitative content analysis to reflect on the knowledge drawn from the artifacts.

Results: The presented study leverages the capabilities of Artificial Intelligence and Blockchain technologies to benefit from the convergence. In line with the concept of 'Texture of Practices,' research provides recommendations to augment the organ transplant system in terms of procurement, coordination, and transplantation.

Limitations: Drawing the knowledge from the case studies, research strives to understand the reality and interaction of actors in a healthcare context. Considering the complex nature of the organ transplant process, the study is limited to the Indian scenario and cannot be generalized.

Contribution: Research identifies the requirement of a unified digital interface and encourages the integration of emergency health services to facilitate operational processes during organ transplants.

Keywords: Healthcare, Organ transplant, A.I., Blockchain, Texture of practices

How to cite: Morande, S., Marzullo, M. (2020). Application of Artificial Intelligence and Blockchain in healthcare management donor organ transplant system. Annals of Management and Organization Research, 1(1), 25-38.

\section{Introduction and research background}

\subsection{Introduction}

Organ transplant is the surgical implantation of an organ with an enormous significance that can save many human lives. (Job \& Antony, 2018) Though there are advances in technology and medicine, the shortage of organs has been recognized worldwide as a significant limiting factor to organ transplantation (Girlanda, 2016a). The presented research is based on the deceased donation that is carried in the absence of a suitable donor in the family. After natural cardiac death, only a few organs can be donated, whereas, after brain death - including vital organs - several other organs can be put for donation. However, there is a massive gap between the number of transplant recipients and the availability of organs in India. Data suggests that the total organ donation shortage of the country can be met with if even 5 to $10 \%$ of potential donors are committed to the cause (Srivastava \& Mani, 2018).

Concurrently several challenges can be faced while meeting the existing demand for the transplant (Mishra et al., 2004). During organ transplants, hearts and other organs must be transported over long 
distances to a patient who needs it in time. India's overcrowded roads are unsuitable for such contingencies. It presents a challenge where traffic on the road hampers organ transport between hospitals. Organs can typically sustain a period during transport called 'ischemia time,' and significant delay can cost a suitable organ to the patient awaiting transplant.

Additionally, as mentioned by Nair (2016), the associated costs of the organ transplant process appear to be exorbitant, and India being a developing country, not every patient from varying economic stratum can afford it. Furthermore, health-related issues escalate due to the aging population, which translates into a multitude of chronic diseases and a burden on the healthcare sector in society (Acampora et al., 2013). Hence, the research focuses on addressing the limitation of resources - in terms of time and cost - using upcoming technologies presented through the lens of 'socio-material view.'

\subsection{Conceptual background}

'Sociomateriality' is a theory that is built upon the intersection of technology and organizational life and attempts to explore the entanglement of actors in a networked system (Monteiro et al., 2012). The research follows a concept called 'Texture of Practices' that invites interaction of participating human as well as existing technologies. Gherardi (2012) proposed the idea of the Texture of Practices to reveal ongoing interactions within interwoven practices. These interwoven practices can be represented as 'Warp' and 'Weft,' where interaction among them results in value creation (Spena \& Mele, 2018).

Prior research observes innovation as a complex, ever-evolving and multidimensional construct made up of Texture of Practices, where -

1) WARP - is a practice of weaving that includes engaging actors and connecting resources for further expansion \&

2) WEFT - is a practice of co-creating that involves generating ideas and sharing insights.

As determined by Leydesdorff et al. (2013), the networked entities in the construct are both human and non-human, where innovation follows a non-linear process.

The presented study explores the 'Warp' and 'Weft' practices in a healthcare ecosystem and investigates the convergence of Artificial Intelligence (A.I.) and Blockchain during the organ transplant process. In line with the Texture of Practices presented study observes the interactions of various actors in order to bridge the gap between the organ donor and recipient. Research further reflects on processes and resources using technologies to address the limitations of time and cost during the donor organ transplant system. It establishes that technologies support the Texture of Practices by reconfiguring itself to human participation and results in the betterment of donor organ transplant systems.

\section{Literature review}

\subsection{Organ donation and transplant}

Although the shortage of organs appears to be a universal problem, India lags far behind other countries. As per the IRODaT (2019), the country has a 0.58 per million donors, which is significantly low when compared to the organ donation rate prevalent in developed nations. Spain leads the world in deceased donor donation programs with the highest national average of the population, and their success can be attributed to trained intensivists. While in the Indian context, hardly any formalized training exists for intensive care doctors or nurses (Palaniswamy et al., 2016).

Nearly every person who dies naturally, or in an accident, is a potential donor. As per Trotter et al. (2018), the organ donors could be categorized in the following two types -

1. Brainstem dead, heart-beating donors/donation after brain death (DBD)

2. Non-heart beating donors/donation after cardiac death (DCD) 
For this research, the brainstem dead type of donors has been considered. Brain death has specific implications for organ donation with the potential for saving numerous lives. (Kumar, 2016)

According to Shemie \& Dhanani (2020), the demand for organ transplants has been increasing, and deceased organ donors serve as a good alternative to meet this demand. That said, in India, the low organ transplant rate can be attributed to limited awareness of healthcare practitioners, which can be due to a lack of mandatory and formal training (Dhanwate, 2014). Although the Indian Transplantation of Human Organ Act in (1994) was amended in 2011, the brain death is not declared immediately in ICUs due to a minimal awareness and doubts regarding the legal procedure.

When brain death occurs, time plays a significant role in the success of a deceased organ donor transplant. A related term called 'cold ischemia time' is used by a medical professional in this context. It refers to the amount of time that an organ can be maintained on a cold preservation fluid without blood supply. Although cold ischemia time varies widely from organ to organ, the organ viability can only be ensured without significant delay in organ transportation (Srivastava \& Mani, 2018). While the organ transplant process is about running against the time, conventional methods of road transport are still being used in India. It has resulted in instances where valuable organs have been wasted due to a delay in transportation. Consequently, the concept of 'Green corridor' was introduced, but existing research indicates that the utility of this solution is still limited (Fatima et al., 2018).

As there is a vast gap between demand and supply, many patients die due to the unavailability of organ donors. At times, there is a lack of coordination observed when the retrieval of the organs is carried outs during the odd hours. India, as a developing country - private air ambulances - incur too much cost while flights are not always available for transporting the organs (Sharma, 2017).

The facts above bring us to another barrier faced during the organ transplant process - 'Costs.' The research looks at relevant issues, using a Socio-material view to provide suitable recommendations so that time and cost factors can be mitigated during the organ transplant process.

\subsection{Socio-material view}

The core of part of this research revolves around the fabric of innovation with a pair of intertwining practices that are termed as 'Texture of Practices.' In the socio-material context, this metaphor is about interconnected practices that move beyond a fixed relationship - and keep redefining itself - for resource integration and value creation purpose. According to Spena \& Mele (2018), treating innovation through 'socio-material view' can present new avenues that connect with,

\section{- $\quad$ Human Touch \\ - Technological Context \\ - $\quad$ Human Side of Smart Systems}

Considering the donor organ transplant system include all of the above elements, the socio-material view becomes very much relevant for a given study. It delivers an idea of a network of entities for the inception of a new context of healthcare management and creating new solutions to address social challenges.

Based on the literature, the research explores the possibility of technology-driven innovations in organ transplant mechanism and its practical nature with respect to the associated costs and availability of time.

\subsection{Technological convergence}

Instead of reinventing the wheel - a set of technological advancements - can bring about groundbreaking changes to the Healthcare industry. In the healthcare sector, technological scenarios combined with innovative practices can deliver unexplored possibilism. Upcoming technologies such as Artificial Intelligence (A.I.) and Blockchain can act as a catalyst for the same. A.I. systems are capable of constructing algorithms from the data, perform specific operations on images to extract useful information, and make predictions. To be more effective as a system, A.I. can make use of the 
Blockchain technological platform to fulfill the promise of pervasive operations. (Morande \& Pietronudo, 2020)

Based on existing use cases, Blockchain is capable of identity management, smart contract generation, and shared ledger management. That said, it can be used for 'One data truth' within healthcare to provide more value by improving the business processes. As per Tapscott \& Tapscott (2017), Blockchain can enable organizations to receive timely information and provides an end to end visibility in a network. According to Diedrich (2016), an application of Blockchain technology beyond digital currencies requires a new technological process. At the moment, such a technological requirement can be fulfilled by Artificial Intelligence systems (Esposito et al., 2018). The same can be leveraged by the healthcare industry with a significant saving of time and cost.

Considering both A.I and Blockchain can be actors within the Texture of Practices, these technologies should not be treated separately as the duality of technology represents both 'objective reality' (technology itself) and 'constructed product' (element of practice). As per Orlikowski (2010), Sociomateriality adopts a practice-based perspective in its overcoming of duality while exploring human-technology relationships. She had earlier argued that even though technology has specific digital properties - the user has the option to explore it - leading to innovation. (Orlikowski, 2002). Collectively using the technological convergence and duality of technology, the proposed research looks forward to presenting the multifaced nature of healthcare practices to tackle societal problems.

\section{Research methodology}

\subsection{Research design}

From a research point of view, the application of emerging technologies has an exploratory as well as applied focus (Barnes et al., 1992). As given research is empowered by the process of comprehensive data collection, the qualitative methodology is justified to explicate complex issues and advance existing knowledge (Dubois \& Gadde, 2002). Since relevant case studies are used in research, their broad understanding provides the researcher with a high degree of flexibility and independence. (Mills et al., 2010)

The research utilizes the framework presented by Bengtsson (2016) to extract the content utilizing coding agenda, and using systematic classification; unstructured data can further be segregated and presented in an informative manner. It also provides 'manifest' and 'latent' analysis to reinforce insightful interpretations.

\subsection{Data collection}

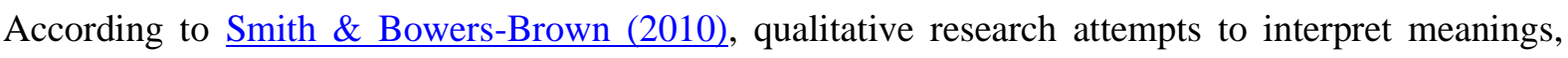
processes, and perceptions by analyzing case studies in their temporal particularity where the ultimate objective is to make sense of the social world (through interpretation) to discover the reality underneath. To facilitate qualitative research, twenty case studies were selected to reflect on the entangled practices in the healthcare sector. As there exists no ideal number of cases to be used for such analysis, multiple relevant cases present a robust outcome (Eisenhardt \& Graebner, 2007).

A purposive case study sampling process was followed, as suggested by Patton (2002), that focused on the organ donation process. The breadth (across available content) and the depth (of the content) were also considered during case selection (Darke et al., 1998). As corroborated by Yin (2003), the case study approach is well established in the social sciences and capable of covering contextual conditions, which might be relevant to the phenomenon being studied. Such a method is also designed to help researchers understand individuals and the socio-cultural contexts (Gummesson, 2017). Such an approach makes it possible to interpret and analyze detailed descriptions that can be transferred to similar situations (Merriam, 1998; Merriam \& Tisdell, 2015). With the help of data analysis tools, replicable and valid inferences can be made from the data according to the context (Krippendorff, 2018). 


\subsection{Data analysis}

The proposed research has utilized 'Qualitative Content Analysis' that is fulfilled using the following:

Analysis Tool - (Qualitative Analysis Software)

$>$ To support the systematization of the content

Analytical Framework - (Bengtsson, 2016)

$>$ To help extraction and analysis of the content

To conduct data analysis, the study opted for Atlas.ti software, since it offers several advantages, enabling visualization and integration that support an exploratory approach leading to accidental discoveries. Atlas.ti offers a promising way of conducting content analysis. The software enables improved data management and effective content-coding that allows researchers to concentrate on data analysis and offers a sophisticated way of exploring the data. (Soratto et al., 2020)

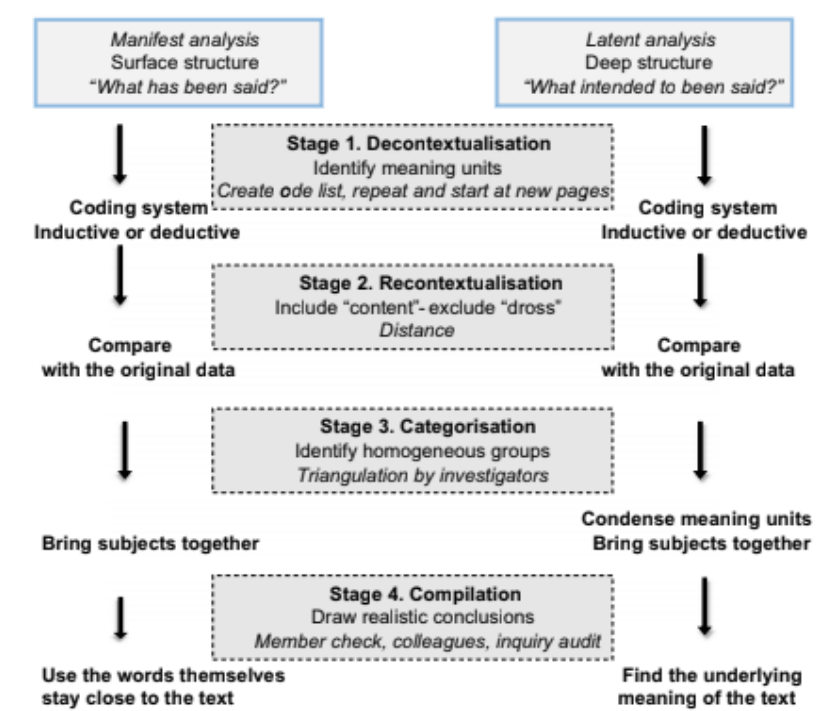

The framework suggested by Bengtsson (2016) codified the text in four metasynthesis stages that include Decontextualization, Re-contextualization, Categorization, and Compilation activities.

During these four stages, researchers identified a deductive coding system and compared it with the original data.

The process resulted in condensing the content and finding the underlying meaning of the textual data, as exhibited in Figure 1.

Figure 1: Data Analysis framework (Credits: Bengtsson, 2016)

The research design also made use of applicable theories in innovation practices, making it interdisciplinary research. The in-depth analysis of content provided a reflection on innovative health solutions driven by Artificial Intelligence (A.I.) and Blockchain technologies.

During the data staging process, new codes were created as themes that began to emerge after multiple readings of the text. This method included:

\section{(1) reading and re-reading the texts \\ (2) identifying and labeling variables into specific categories, properties, and concepts; and \\ (3) establishing inter-relationships of codes across categories and concepts}

The content analysis allowed for the emergence of coding schemes and lead to the creation of the codebook. Inter-rater reliability was integral from the beginning of the process, where each case study was assigned a primary coder and a secondary coder who reviewed and validated the coding. (Riccardi et al., 2017).

Systematic data extraction, as per Figure 1, expedited the emergence of new practices to support innovation in the organ transplant process. When mapped using the codebook - content analysis identified the influence of machine learning algorithms and consensus mechanisms. It also signified a personalized assessment driven by health-related data. A careful look at the healthcare and organ matching practices reflected on allocation decisions as well as retrieval /preservation processes during organ transplants. 
The dynamics and implications of the interconnected social and technological phenomena reflected on the importance of the integrity of data and the feasibility of the transplant process. Multiple sources of data and numerous actors helped triangulate the data and allowed significant insights to emerge (Myers, 2009; Ponelis, 2015; Yin, 2003).

\section{Results and discussions}

\subsection{Results}

Based on the qualitative content analysis with 38 Codes and 195 quotations, data was extracted from the twenty case studies. As per Figure 2, the set of technologies (including A.I. and Blockchain ) appeared interdependent and adapted itself to manifest opportunities within the donor organ transplant system. Such manifestation was apparent in the organization of transplant mechanism that revealed current limitations of processes and called for optimization of resources. It further supported the notion of re-designing of organ transplant mechanism through resource integration. Additionally, the significance of time and costs elicited the need for integrated access for value co-creation.

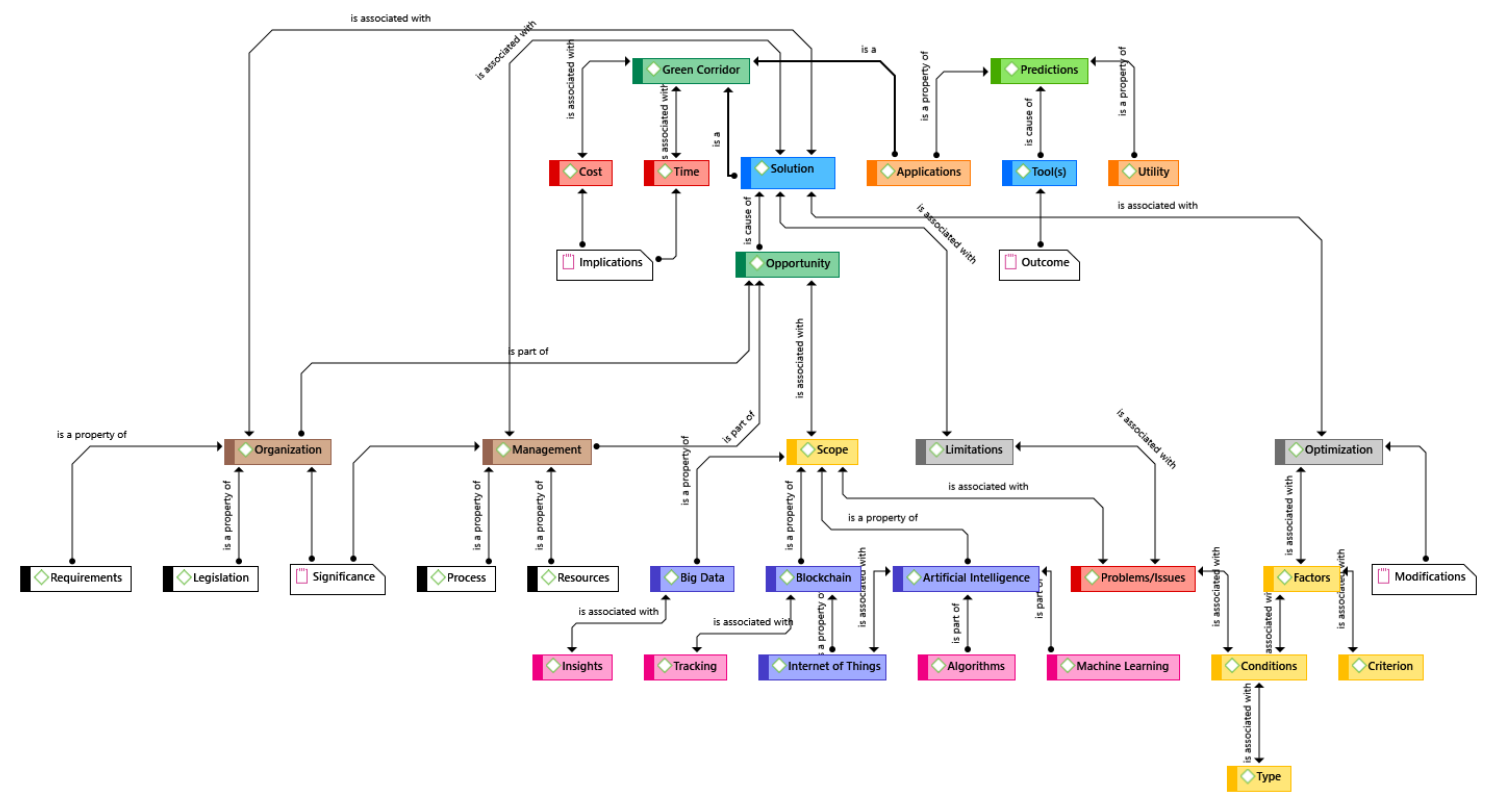

Figure 2: Content Analysis (Schema without quotations)

As per the content schema in Figure 2, the healthcare 'process' and 'legislation' appeared to be an integral part of the solution. The 'Manifest analysis' \& 'Latent analysis' outlined by Bengtsson (2016) highlighted the same. Several permutations of actors came into play during a deceased donor transplant process.

\subsection{Observations}

The organ 'suitability' is the most critical factor during the organ transplant process (refer to conditions $\&$ criterion). Organ suitability is affected by the time (Cold ischemia) that is spent deciding on various considerations, as shown in the content analysis (Figure 2). The organ matching process can be supported using Blockchain and A.I. technologies, where health conditions of donor and receiver can be tracked using Blockchain (based on the inputs from other technologies), and the assessment of compatibility can be fulfilled by the A.I. system to complement human decision making. Practices in the organ transplant can be seen as complex networks of heterogeneous elements that are kept together by processes and performativity (Gherardi, 2012). The 'performativity view' of practices contributes to the advancement of notions by continuously changing reality, rather than merely reproducing it (Hultin, 2019; Spena \& Mele, 2018).

\subsection{Discussions}


For the presented research design, the Qualitative method is highly appropriate, where pre-emptive reduction of the data prevents discovery (Atieno OP, 2009). Further, the applied design promotes sagacity, expanding it to include findings via unexpected means and eventually providing serendipitous results. (Kefalidou \& Sharples, 2016; Mills et al., 2010; Nutefall \& Ryder, 2010). Pursuant to Almeida et al. (2017), qualitative research offers an excellent opportunity for innovation; however, it is challenging to establish cause-effect connections. Therefor to systematize and investigate the case studies, illustrations from Atlas.ti software were extensively used. Based on the 'Word Cloud' extracted from the content analysis, as per Figure 3, the organ transplant process includes procurement, coordination, and transplantation as primary activities.

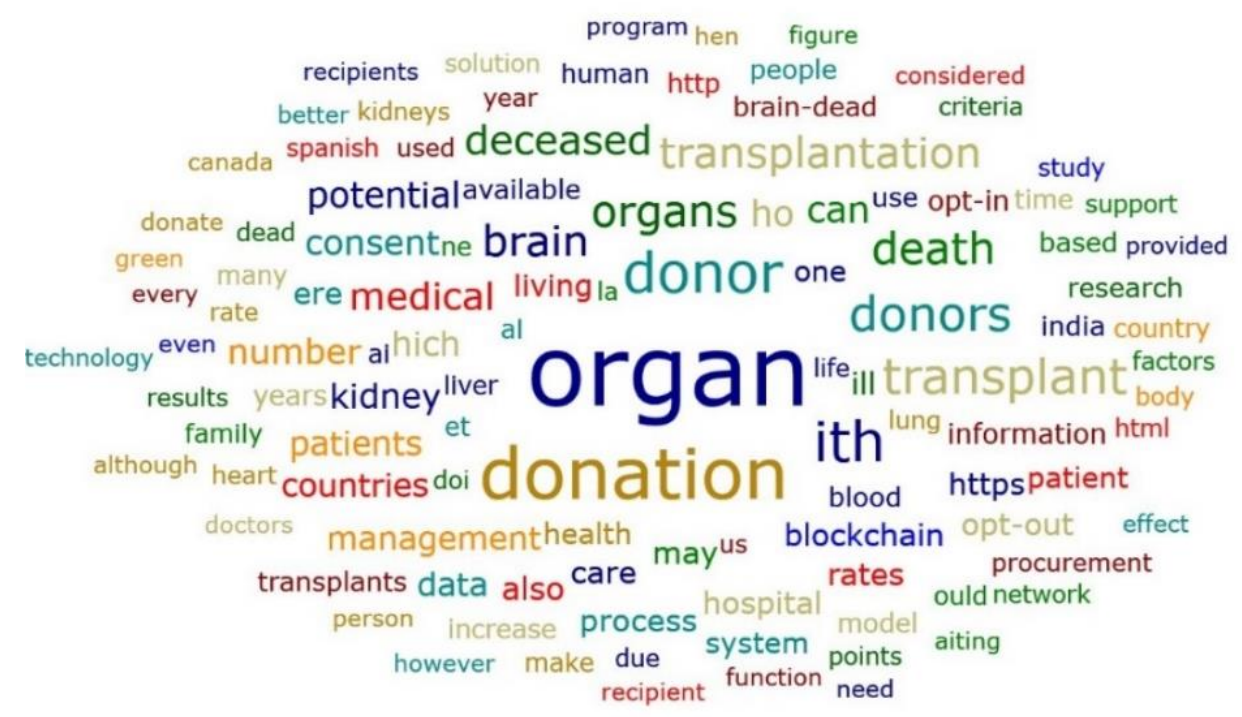

Figure 3: Word Cloud displaying processes during organ transplant

After the content analysis, a holistic review of the data pattern was carried out using Atlas.ti. to leverage the potential of automation to identify new connections (Woods et al., 2016). In Qualitative Content Analysis, the term 'Groundedness' refers to the number of quotations linked to code, and 'Density' refers to the number of other codes connected to a code (Cope, 2009). The connection between these critical terms demonstrates qualitative epistemology with the interpretivist philosophical stance that extends insights using digital technology (Zakaria \& Zakaria, 2016).

In the donor organ transplant system, A.I. uses machine learning models that not only connect organ donors to recipients but also predict the probability of an organ matching for longevity.

Blockchain uses the immutability of records and traceability of conditions to keep track of patient conditions, facilitating the exchange of information from origin to destination (Alandjani, 2019; Kulshrestha et al., 2020).

Machine Learning models support transplant patients to monitor and manage body vitals during the transplant process. Blockchain's capability to track transportation state and ambient condition maintains an active role in monitoring organ health. The convergence of A.I. and Blockchain systems extends organ matching capability that extends help to multiple individuals receive a transplant via a single organ donor. (Díez-Sanmartín \& Sarasa Cabezuelo, 2020) Besides, the donor organ transplant system also guarantees that organs are not deteriorated by providing sophisticated management of the entire process.

To attain greater depths of discussion, six case studies were selected based on greater relevance demonstrated by the number of 'Quotations,' and six codes were assigned using higher 'Groundedness' as a parameter for selection. A Co-occurrence table was generated displaying the Column-relative frequencies, as shown in Table 1. As the co-occurrence table (Table 1) demonstrates, 'Complexity' based on the condition $(\mathrm{Gr}=24)$, factors $(\mathrm{Gr}=17)$, and processes $(\mathrm{Gr}=14)$ together constitute 
Groundedness of 20.07\%. It represents the resource integration as 'WARP.' Insights ( $\mathrm{Gr}=24)$ along with process $(\mathrm{Gr}=14)$ present opportunity $(\mathrm{Gr}=17)$ with Groundedness of $79.93 \%$ display related 'Performativity.' It holistically represents the co-creation process as 'WEFT.' The degree of innovation constitutes gradual interaction between the Texture of Practices. (West et al., 2003)

\section{Table 1: Co-occurrence table with Column-relative frequencies}

Using the Texture of Practices, the healthcare ecosystem can leverage the existing solutions to avoid delays in the organ transplant process. The emergency services can also be re-designed to reduce related costs. Although in the Indian healthcare context, there are limitations on providing emergency airlifting services (in terms of costs) and developing Green Corridors (in terms of time), the opportunities expressed during the content analysis process (Refer to Table 1) leaves a room to address problems

\begin{tabular}{|c|c|c|c|c|c|c|}
\hline & $\begin{array}{l}\text { Organ } \\
\text { Donor } \\
\text { Problems } \\
\text { Gr=35 }\end{array}$ & $\begin{array}{l}\text { Green } \\
\text { Corridor } \\
\text { Gr=12 }\end{array}$ & $\begin{array}{l}\text { Strategies to } \\
\text { optimize } \\
\text { deceased } \\
\text { organ } \\
\text { donation } \\
\text { Gr=14 }\end{array}$ & $\begin{array}{l}\text { Deceased } \\
\text { organ donation } \\
\text { for } \\
\text { transplantation } \\
\text { Gr=19 }\end{array}$ & $\begin{array}{l}\text { Organ } \\
\text { donation and } \\
\text { A.I. } \\
\text { Gr=11 }\end{array}$ & $\begin{array}{l}\text { Blockchain- } \\
\text { based } \\
\text { Organ } \\
\text { Transplant } \\
\text { Services } \\
\text { Gr=17 }\end{array}$ \\
\hline $\begin{array}{l}\text { Gr}=24 \\
\text { Conditions }\end{array}$ & $41.38 \%$ & $0.00 \%$ & $7.14 \%$ & $0.00 \%$ & $0.00 \%$ & $0.00 \%$ \\
\hline $\begin{array}{ll} & \text { Factors } \\
\end{array}$ & $37.93 \%$ & $0.00 \%$ & $0.00 \%$ & $0.00 \%$ & $0.00 \%$ & $14.29 \%$ \\
\hline $\begin{array}{ll}\bullet & \text { Insights } \\
\text { Gr=24 }\end{array}$ & $3.45 \%$ & $0.00 \%$ & $21.43 \%$ & $36.36 \%$ & $33.33 \%$ & $42.86 \%$ \\
\hline $\begin{array}{l}\bullet \quad \text { Opportunity } \\
\text { Gr=17 }\end{array}$ & $3.45 \%$ & $42.86 \%$ & $42.86 \%$ & $9.09 \%$ & $33.33 \%$ & $42.86 \%$ \\
\hline $\begin{array}{l}\text { - Problems/Issues } \\
\text { Gr=24 }\end{array}$ & $10.35 \%$ & $57.14 \%$ & $21.43 \%$ & $45.45 \%$ & $33.33 \%$ & $0.00 \%$ \\
\hline $\begin{array}{ll}\text { Gr }=14 & \text { Process } \\
\end{array}$ & $3.45 \%$ & $0.00 \%$ & $7.14 \%$ & $9.09 \%$ & $0.00 \%$ & $0.00 \%$ \\
\hline
\end{tabular}

related to Time and Costs.

The application of A.I. (Decision making) and Blockchain (Traceability) represent pervasive impact using the convergence of A.I. and Blockchain (Efanov \& Roschin, 2018). Based on the above observation (Table 1) and content analysis (Figure 2), the socio-material view has non-human (technology) along with human-driven (conditions) processes. It ultimately calls for a unified interface to be developed for medical professionals as well as for patients to support the donor organ transplant system. It is believed that such an interface can resolve issues related to time.

Gherardi (2012) believes practices are networks of heterogeneous elements kept together by active processes of relationships, actions, and performativity. The performativity view of practices contributes to advancing the notion that practices change either incrementally or radically through their enactment. Conforming to Rahman (2016), the fray of associated problems, processes, opportunities, conditions, and factors can give rise to innovative practices, eliciting deeper insights from the interpretation of case studies. The metaphor of a Texture of Practices acknowledges how practices rest on other practices and thereby move beyond solely economic focus to emphasize the socio- contextual nature of innovating. (Mele \& Russo-Spena, 2017; Spena \& Mele, 2018). The execution of practices continuously shapes and formats reality, rather than simply reproducing it. It advances the notion of innovation as an emergent process involving an interconnected set of actors. (Lusch \& Nambisan, 2015)

In line with the above discussions, a scatter plot was developed from the Code document table using six codes carrying the highest Groundedness and significant Density. As shown in Figure 4, QCA presented a significant degree of code density and Groundedness where

- Issues (Density=3 and Grounded $=24$ ) shows the severity of the problems in terms of time and costs of organ transplant. 
- Process (Density=1 and Grounded $=14$ ) reflect the complexity of the process in terms of allocation, retrieval /preservation of organs.

- Insights (Density=1 and Grounded =24) provide clarity to resolve the issues related to organ transplants.

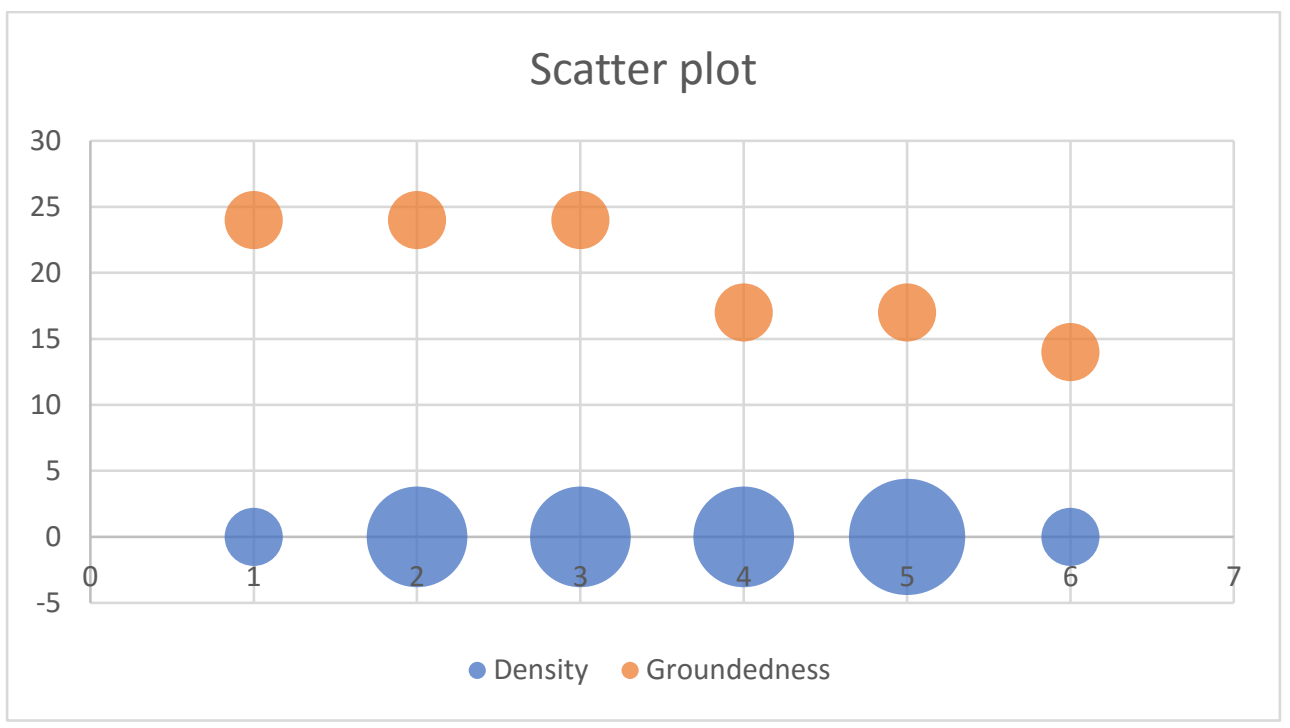

Figure 4: Scatter plot displaying the impact of Texture of Practices

Figure 4 also displays the outcome of content analysis where complex practices (in healthcare) provide opportunities (in the organ transplant process) to address problems or related issues of cost and time. Such a process of interaction among factors where higher degree of Density (4) and Groundedness (17) gives rise to innovation.

According to Spena \& Mele (2018), the process of innovation can be deduced from the pairs of intertwining Texture of Practices that results in value co-creation. Figure 4 indicates the same, where the WARP and WEFT practices lead to innovation in donor transplant programs. When mapped to the donor organ transplant system, these innovative practices can yield optimal utility during the organ transplant process.

According to De-Pablos-Heredero et al. (2015), Organ transplant systems present two essential characteristics: Interdependence and Capacity of adaptation. Both characteristics make the management and evaluation of these systems complex. In Donor Organ Transplant Systems, organ transportation comes as one of the most significant processes. The performativity view in proposed qualitative research suggests that Organ transportation should leverage the existing system of emergency service available in India. Such an approach may significantly reduce the associated costs during organ transplants.

As per the reflection from Figure 4, emergency service can be integrated with the organ transplant system for efficient procurement, coordination, and transplantation. The resource integration achieved in this process reflects the value that the community may receive in terms of an efficient Organ Transplant Systems. This approach of re-designing of emergency services requires minimal modifications in existing regulations that resonate with the time and costs saving. Thus, the transformation of deceased donor transplant programs can be fulfilled and made accessible to a greater number of potential candidates (Girlanda, 2016b).

\subsection{Insights}

The research fulfills the Systems theory proposed by Bertalanffy (1968) by displaying the outcome of technologies that cannot be separated. It further shows that technology contains duality, where it acts as both operant and operand (Feldman \& Orlikowski, 2011). 
The content analysis of the Healthcare ecosystem indicates that 'Complexity' is one of its main characteristics. At the same time, proactive management of healthcare practices is the outcome of 'Performativity' that keeps on changing reality. (Capra, 1996; Gherardi, 2012)

\section{Conclusion}

\subsection{Inference}

In consonance with parallel studies on an organ transplant system, it can be inferred that the donor organ transplant system requires effective operational management and streamlined coordination. The process of deceased donor transplants is time-sensitive, where both human and non-human actors come into the play. Presented research observes a set of actors within which relationships are being established and re-established to drive the optimal outcome. Research discovers data-driven A.I. and Blockchain convergence to consider organ donation criteria, which relates to both the donors as well as the receivers.

Using the data-driven model of A.I. systems, it is possible to analyze the likelihood of successful transplants by considering several permutation and combinations. Blockchain provides a secure and transparent platform to facilitate organ transplantation. This new context gives rise to technologymediated techniques for efficient procurement, coordination, and transplantation in donor organ transplant system. Although technological re-configuration can be perceived in the given study, human intervention is also essential for the feasibility and success of organ transplants. Technologies alter the broad nature of practices by reconfiguring the contribution of human participation leading to optimization of time and costs.

In a dynamic environment presented by the Texture of Practices, performativity - inspired by the convergence of technologies - yields the necessity of developing an interface that facilitates the vital flow of information to healthcare stakeholders. One of the other significant insights supported by 'Texture of Practices' advocates the importance of integrating donor organ transplant systems with existing emergency services. Through such activities, a proactive donor organ transplant system can be developed to tackle issues related to the Indian healthcare system.

\subsection{Policy and managerial implications}

With an intricate problem in place, the donor transplant rate directly affects the organ suitability, where this study provides significant depth. Research further contemplates on factors that influence organizational activities during the organ transplant. With a holistic understanding of the current state of the donor organ transplant system in India, the following implications are possible through the presented research -

\subsubsection{Policy implications}

As research identifies considering the significance of time and cost, modification is required to legislations and regulations for,

- Standardization of organ transplant processes

It may include consideration of the formalization of training programs for intensivist that may accelerate the systematized transplant process

\subsubsection{Managerial implications}

The informational resources outlining the deceased organ donation process are limited in the Indian context; hence there should be more awareness using,

- Creation of access point to retrieve essential information

A unified interface can be designed to connect with digital touchpoints for patients as well as a medical professional that may also put an end to unethical practices. 


\section{Limitation and study forward}

In Qualitative research, there are constraints on generalizability, applications to practice, or utility of findings. In the given study, the insights are limited to the Indian context. The method used to establish internal and external validity may also face unanticipated challenges. (Chowdhury, 2015). From the analysis and discussions, it can be implied that there is a necessity for modifications of existing infrastructure regarding organ donation. As one of the accidental discoveries of the given study refers to the inclusion of emergency health services for resource integration, future research looks forward to investigating the quantification of such integration within the organ transplant system.

Research suggests that lower organ transplant rates can be attributed to limited transplant guidelines and ineffective coordination. Hence future research would explore the type of information that should be readily available for organ donors/recipients and doctors/healthcare professionals to facilitate the organ transplant. Further, in order to break away from the current limitations, future research plans to map and generalize this research in a European context.

\section{Acknowledgment}

This research received no external funding. A premium version of Atlas.ti 8 (MS-Windows) was used for data analysis and illustrations. The author declares no conflict of interest.

\section{References}

Acampora, G., Cook, D. J., Rashidi, P., \& Vasilakos, A. V. (2013). A Survey on Ambient Intelligence in Healthcare. Proceedings of the IEEE, 101(12), 2470-2494. https://doi.org/10.1109/JPROC.2013.2262913

Alandjani, G. (2019). Based Medical Transaction Scheme for. November, 41-63.

Almeida, F., Superior, I., Gaya, P., Queirós, A., \& Faria, D. (2017). Strengths and Limitations of Qualitative and Quantitative Research Methods Innovation and Entrepreneurship View project Observatory of Portuguese Academic Spin-offs View project European Journal of Education Studies STRENGTHS AND LIMITATIONS OF QUALITATIV. September. https://doi.org/10.5281/zenodo.887089

Atieno OP. (2009). An analysis of the strengths and limitation of qualitative and quantitative research paradigms. Problems of Education in the 21st Century, 13, 13-18. https://doi.org/10.1073/pnas.0502680102

Barnes, D. J., Buckland, B. K., \& Brancheau, J. C. (1992). Methodological issues in emerging technologies research: experiences and recommendations. Proceedings of the Twenty-Fifth Hawaii International Conference on System Sciences, iv, 325-336 vol.4. https://doi.org/10.1109/HICSS.1992.183356

Bengtsson, M. (2016). How to plan and perform a qualitative study using content analysis. NursingPlus Open, 2, 8-14. https://doi.org/10.1016/j.npls.2016.01.001

Bertalanffy, L. Von. (1968). No Title.

Capra, F. (1996). THE WEB OF LIFE : A New Synthesis of Mind and Matter.

Chowdhury, I. A. (2015). Issue of quality in a qualitative research: An overview. Innovative Issues and Approaches in Social Sciences, 8, 142-162. https://doi.org/10.12959/issn.18550541.IIASS-2015-no1-art09

Cope, M. (2009). Grounded Theory. In International Encyclopedia of Human Geography (pp. 647650). https://doi.org/10.1016/B978-008044910-4.00450-8

Darke, P., Shanks, G., \& Broadbent, M. (1998). Successfully completing case study research: combining rigour, relevance and pragmatism. Information Systems Journal, 8(4), 273-289. http://www.blackwell-synergy.com.ludwig.lub.lu.se/doi/pdf/10.1046/j.13652575.1998.00040.x?cookieSet=1

De-Pablos-Heredero, C., Fernández-Renedo, C., \& Medina-Merodio, J. A. (2015). Technical efficiency and organ transplant performance: A mixed-method approach. International Journal of Environmental Research and Public Health, 12(5), 4869-4888. https://doi.org/10.3390/ijerph120504869 
Dhanwate, A. D. (2014). Brainstem death: A comprehensive review in Indian perspective. Indian Journal of Critical Care Medicine: Peer-Reviewed, Official Publication of Indian Society of Critical Care Medicine, 18(9), 596.

Diedrich, H. (2016). Ethereum: blockchains, digital assets, smart contracts, decentralized autonomous organizations. Wildfire Publishing.

Díez-Sanmartín, C., \& Sarasa Cabezuelo, A. (2020). Application of Artificial Intelligence Techniques to Predict Survival in Kidney Transplantation: A Review. Journal of Clinical Medicine, 9(2), 572. https://doi.org/10.3390/jcm9020572

Dubois, A., \& Gadde, L.-E. (2002). Systematic combining: an abductive approach to case research. Journal of Business Research, 55(7), 553-560.

Efanov, D., \& Roschin, P. (2018). The all-pervasiveness of the blockchain technology. Procedia Computer Science, 123, 116-121. https://doi.org/10.1016/j.procs.2018.01.019

Eisenhardt, K. M., \& Graebner, M. E. (2007). Theory building from cases: Opportunities and challenges. Academy of Management Journal, 50(1), 25-32.

Esposito, C., De Santis, A., Tortora, G., Chang, H., \& Choo, K.-K. R. (2018). Blockchain: A panacea for healthcare cloud-based data security and privacy? IEEE Cloud Computing, 5(1), 31-37.

Fatima, S., Kunkulol, R., Gangadhar, A. H., Megha, S., Kunwar, V., Deepak, P. R., Nair, A., \& Arun, P. R. (2018). Awareness about the concept of Green Corridor among medical student and doctors in a Rural Medical College of Maharashtra, India. International Journal of Clinical and Biomedical Research, 38-43.

Feldman, M. S., \& Orlikowski, W. J. (2011). Theorizing Practice and Practicing Theory. Organization Science, 22(5), 1240-1253. https://doi.org/10.1287/orsc.1100.0612

Gherardi, S. (2012). Why do practices change and why do they persist? Models of explanations. In Practice, learning and change (pp. 217-231). Springer.

Girlanda, R. (2016a). Deceased organ donation for transplantation: Challenges and opportunities. World Journal of Transplantation, 6(3), 451.

Girlanda, R. (2016b). Deceased organ donation for transplantation: Challenges and opportunities. World Journal of Transplantation, 6(3), 451. https://doi.org/10.5500/wjt.v6.i3.451

Gummesson, E. (2017). From relationship marketing to total relationship marketing and beyond. Journal of Services Marketing.

Hultin, L. (2019). On becoming a sociomaterial researcher: Exploring epistemological practices grounded in a relational, performative ontology. Information and Organization, 29(2), 91-104. https://doi.org/10.1016/j.infoandorg.2019.04.004

IRODaT. (2019). International Registry in Organ Donation and Transplantation. www.irodat.org

Job, K., \& Antony, A. (2018). Organ Donation and Transplantation: "Life after Death." Organ Donation and Transplantation: Current Status and Future Challenges, 17.

Kefalidou, G., \& Sharples, S. (2016). Encouraging serendipity in research: Designing technologies to support connection-making. International Journal of Human Computer Studies, 89, 1-23. https://doi.org/10.1016/j.ijhcs.2016.01.003

Krippendorff, K. (2018). Content analysis: An introduction to its methodology. Sage publications.

Kulshrestha, A., Mitra, A., \& Amisha. (2020). Securing Organ Donation using Blockchain. International Journal of Scientific \& Engineering Research, 11(6), 147-151.

Kumar, L. (2016). Brain death and care of the organ donor. Journal of Anaesthesiology, Clinical Pharmacology, 32(2), 146-152. https://doi.org/10.4103/0970-9185.168266

Leydesdorff, L., Rotolo, D., \& de Nooy, W. (2013). Innovation as a nonlinear process, the scientometric perspective, and the specification of an "innovation opportunities explorer." Technology Analysis and Strategic Management, 25(6), 641-653. https://doi.org/10.1080/09537325.2013.801948

Lusch, R. F., \& Nambisan, S. (2015). Service innovation: A service-dominant logic perspective. MIS Quarterly: Management Information Systems, 39(1), 155-175. https://doi.org/10.25300/MISQ/2015/39.1.07

Mele, C., \& Russo-Spena, T. (2017). Innovating as a texture of practices. In Innovating in practice (pp. 113-137). Springer.

Merriam, S. B. (1998). Qualitative research and case study applications in education. 
Merriam, S. B., \& Tisdell, E. J. (2015). Qualitative research: A guide to design and implementation. John Wiley \& Sons.

Mills, A., Durepos, G., \& Wiebe, E. (2010). Encyclopedia of Case Study Research. https://doi.org/10.4135/9781412957397 NV - 0

Mishra, M. N., Saxena, V. K., \& Narula, A. S. (2004). Differences in renal transplantation in India and first world countries. International Journal of Human Genetics, 4(2), 161-165.

Monteiro, E., Almklov, P., \& Hepsø, V. (2012). Living in a sociomaterial world. In Shaping the future of ICT research. Methods and approaches (pp. 91-107). Springer.

Morande, S., \& Pietronudo, M. C. (2020). Pervasive Health Systems: Convergence through Artificial Intelligence and Blockchain Technologies. Journal of Commerce and Management Thought, 11(2), 155. https://doi.org/10.5958/0976-478x.2020.00010.5

Myers, M. D. (2009). Qualitative Research in Business \& Management Sage Publications. London, $U K$.

Nair, P. (2016). Organ is free, transplant cost is problem - Times of India. Times of India. https://timesofindia.indiatimes.com/life-style/health-fitness/health-news/Organ-is-freetransplant-cost-is-problem/articleshow/54014378.cms

Nutefall, J. E., \& Ryder, P. M. (2010). The Serendipitous Research Process. Journal of Academic Librarianship, 36(3), 228-234. https://doi.org/10.1016/j.acalib.2010.03.005

Orlikowski, W. J. (2002). Knowing in practice: Enacting a collective capability in distributed organizing. Organization Science, 13(3), 249-273.

Orlikowski, W. J. (2010). Technology and organization: Contingency all the way down. Research in the Sociology of Organizations, 29, 239-246.

Palaniswamy, V., Sadhasivam, S., Selvakumaran, C., Jayabal, P., \& Ananth, S. R. (2016). Organ donation after brain death in India: A trained intensivist is the key to success. Indian Journal of Critical Care Medicine: Peer-Reviewed, Official Publication of Indian Society of Critical Care Medicine, 20(10), 593.

Patton, M. Q. (2002). Two decades of developments in qualitative inquiry: A personal, experiential perspective. Qualitative Social Work, 1(3), 261-283.

Ponelis, S. R. (2015). Using interpretive qualitative case studies for exploratory research in doctoral studies: A case of information systems research in small and medium enterprises. International Journal of Doctoral Studies, 10, 535-550. https://doi.org/10.28945/2339

Rahman, M. S. (2016). The Advantages and Disadvantages of Using Qualitative and Quantitative Approaches and Methods in Language "Testing and Assessment" Research: A Literature Review. Journal of Education and Learning, 6(1), 102. https://doi.org/10.5539/jel.v6n1p102

Riccardi, F., Mizrahi, T., Garcia, M. L., \& Korazim-K\&\#337;r\&\#246;sy, Y. (2017). Using ATLAS.ti in Qualitative Research for Analyzing Inter-Disciplinary Community Collaboration. https://doi.org/10.4135/9781473995895

Sharma, P. (2017). The truth about organ transport and transplantation in In. India Today. https://www.indiatoday.in/mail-today/story/organs-transplant-organ-transport-system-indiadonating-organs-962150-2017-02-23

Shemie, S. D., \& Dhanani, S. (2020). The Physiology of Brain Death and Organ Donor Management. Pediatric Critical Care Medicine, 497-518. http://europepmc.org/abstract/PMC/PMC7121438

Smith, M., \& Bowers-Brown, T. (2010). Practical Research and Evaluation : A Start-to-Finish Guide for Practitioners Different Kinds of Qualitative Data Collection Methods. 111-125.

Soratto, J., Pires, D. E. P. de, \& Friese, S. (2020). Thematic content analysis using ATLAS.ti software: Potentialities for researchs in health. Revista Brasileira de Enfermagem, 73(3), 3-7. https://doi.org/10.1590/0034-7167-2019-0250

Spena, T. R., \& Mele, C. (2018). Practising innovation: A sociomaterial view. Editoriale scientifica.

Srivastava, A., \& Mani, A. (2018). Deceased organ donation and transplantation in India: Promises and challenges. Neurology India, 66(2), 316.

Tapscott, D., \& Tapscott, A. (2017). How Blockchain will change organizations. MIT Sloan Management Review, 58(2), 10.

Trotter, P. B., Jochmans, I., Hulme, W., Robb, M., Watson, C., Neuberger, J., \& Andrew Bradley, J. (2018). Transplantation of kidneys from DCD and DBD donors who died after ligature 
asphyxiation: The UK experience. American Journal of Transplantation : Official Journal of the American Society of Transplantation and the American Society of Transplant Surgeons, 18(11), 2739-2751. https://doi.org/10.1111/ajt.14989

West, M., Borrill, C., Dawson, J., Brodbeck, F., Shapiro, D., \& Haward, B. (2003). Leadership Clarity and Team Innovation in Health Care. The Leadership Quarterly, 14, 393-410. https://doi.org/10.1016/S1048-9843(03)00044-4

Woods, M., Paulus, T., Atkins, D. P., \& Macklin, R. (2016). Advancing Qualitative Research Using Qualitative Data Analysis Software QDAS? Soc. Sci. Comput. Rev., 34(5), 597-617. https://doi.org/10.1177/0894439315596311

Yin, R. K. (2003). Case study research: Design and methods (Vol. 5).

Zakaria, N., \& Zakaria, N. (2016). Qualitative Content Analysis: A Paradigm Shift from Manual Coding to Computer-Assisted Coding Using ATLAS.ti.

https://doi.org/10.4135/978144627305015599170 